\title{
Family Physician-Led Group Visits for Lifestyle Modification in Women with Weight Problems: A Pilot Intervention and Follow-Up Study
}

\author{
Merthan Tunay ${ }^{a} \quad$ Hatice Kurdak $^{a}$ Sevgi Özcan ${ }^{a}$ Çiğdem Özdemir ${ }^{b}$ \\ Zeliha Yelda Özer ${ }^{a}$ \\ a Department of Family Medicine, Faculty of Medicine, Çukurova University, Adana, Turkey; \\ ${ }^{b}$ Department of Sports Physiology, Faculty of Medicine, Çukurova University, Adana, Turkey
}

\section{Keywords}

Obesity management · Group medical visits · Family physician

\begin{abstract}
Objective: Lifestyle modification requires extensive information sharing and counseling. However, one-on-one primary care consultations are lacking to cover all necessary components due to time constraints. This preliminary study aims to investigate the feasibility and effects of lifestyle-changing intervention by family physician-led group visits (GVs) on weight management in overweight and obese women. Methods: 60 volunteers fulfilling the inclusion criteria were enrolled. Baseline and 6 th month assessments consisted of anthropometric measurements, SF-36 Health Survey, blood variables, exercise test, and resting metabolic rate. Weight maintenance was controlled at the 12th month. Results: Although weight loss among participants varied, the mean body weights were significantly decreased by $8.2 \%$ in full-attenders $(n=30)$. A significant increase in HDL-cholesterol and decreases in heart rate and blood pressure were found. SF-36 summary scales were significantly improved. Weight change was moderately correlated with exercise duration, compliance to diet, and baseline mental component score. It was determined that $62.5 \%$ of the participants either lost or maintained body weight at the 12th month. Conclusion: Significant weight loss and quality of life improvement was achieved in this pilot study. GVs may be a promising alternative to primary care consultations for obesity management; however, the high dropout level and diverse outcomes need further assessment.

(C) 2018 The Author(s)

Published by S. Karger GmbH, Freiburg
\end{abstract}


Tunay et al.: Family Physician-Led Group Visits for Lifestyle Modification in Women with Weight Problems: A Pilot Intervention and Follow-Up Study

\section{Introduction}

Obesity is a complex health issue that arises from multiple leading and contributing factors, including unhealthy lifestyles. Because of the complexity of these factors, it is difficult to lose weight in the first place and then to maintain it. Hence, obesity management requires extensive information sharing and counseling directed to modify unhealthy lifestyle choices [1].

Primary care consultations traditionally take place in a one-on-one format, and their average length is between 8 to $16 \mathrm{~min}$ in European countries. Although such durations were found to be prolonged for some countries, it is also reported that such a prolongation alone is not sufficient to induce health promotion and behavioral modifications [2-4]. With its rapidly increasing prevalence and intricate nature, obesity emerges as a chronic health problem, which may not be solved through conventional approaches due to time constraints.

In the past two decades, there has been a growing interest in group appointments as a means of addressing the shortcomings of the one-on-one encounter. The group visits (GVs) model was developed in 1996 as an innovative way to solve chronic diseases' management constrains The GVs, alternatively referred to as 'group medical visits' or 'shared medical appointments', include components of a regular office visit but provide increased time with the physician for the patients and allow them to learn from each other. GVs provide patients with high-quality medical care and the support of a group environment. The motivation and support that the group members provide each other has made GVs a preferred procedure to learn self-care during the disease-overcoming period in complex chronic diseases $[5,6]$. A recent systemic review where group-based interventions were compared with individual attempts concluded that group-based approaches are more efficient in the treatment of adult obesity. In addition, it was also emphasized in this study that the research included was carried out mostly by dietitians and psychiatrists [7]. Primary care, where chronic diseases show higher prevalence, is deemed as a significant resource to solve the problem of obesity because of the longitudinal sustainability in physician-patient relationship. However, daily patient log of primary care is quite high in our country, and there are not any programs commonly used for obesity [2]. Since it is a new practice concept for our primary care, it is difficult to predict the feasibility of group medical visit. From this point of view, the primary objective of this pilot study is to examine the feasibility and effects of 6-month family physician-led GVs to provide a healthy lifestyle modification aiming at weight loss and weight loss maintenance in overweight and obese women. The secondary objective is to review the effect of the weight loss obtained as a result of GVs on quality of life and health parameters.

\section{Material and Methods}

\section{Intervention Design}

In the present study, a total of eight GVs were performed within 24 weeks between January 2014 and June 2014 for each group. The first two visits were held every 2 weeks; second two visits were every three weeks, and the final four visits were every four weeks. At the end of 48 weeks, weight maintenance was monitored. GVs took place at the Outpatient Clinic of Cukurova University, Family Medicine Department. Meetings were performed in a seminary room furnished in U shape. The Ethics Committee of Çukurova University Faculty of Medicine has approved this study, and all participants provided their informed written consent. All procedures performed in this study were in accordance with the ethical standards of the Declaration of Helsinki in its revised version of 1975 and its later amendments [8]. Participants were not charged for the GVs and tests performed. The study followed the transparent reporting of evaluations with nonrandomized designs (TREND) statement for reporting. 
Tunay et al.: Family Physician-Led Group Visits for Lifestyle Modification in Women with Weight Problems: A Pilot Intervention and Follow-Up Study

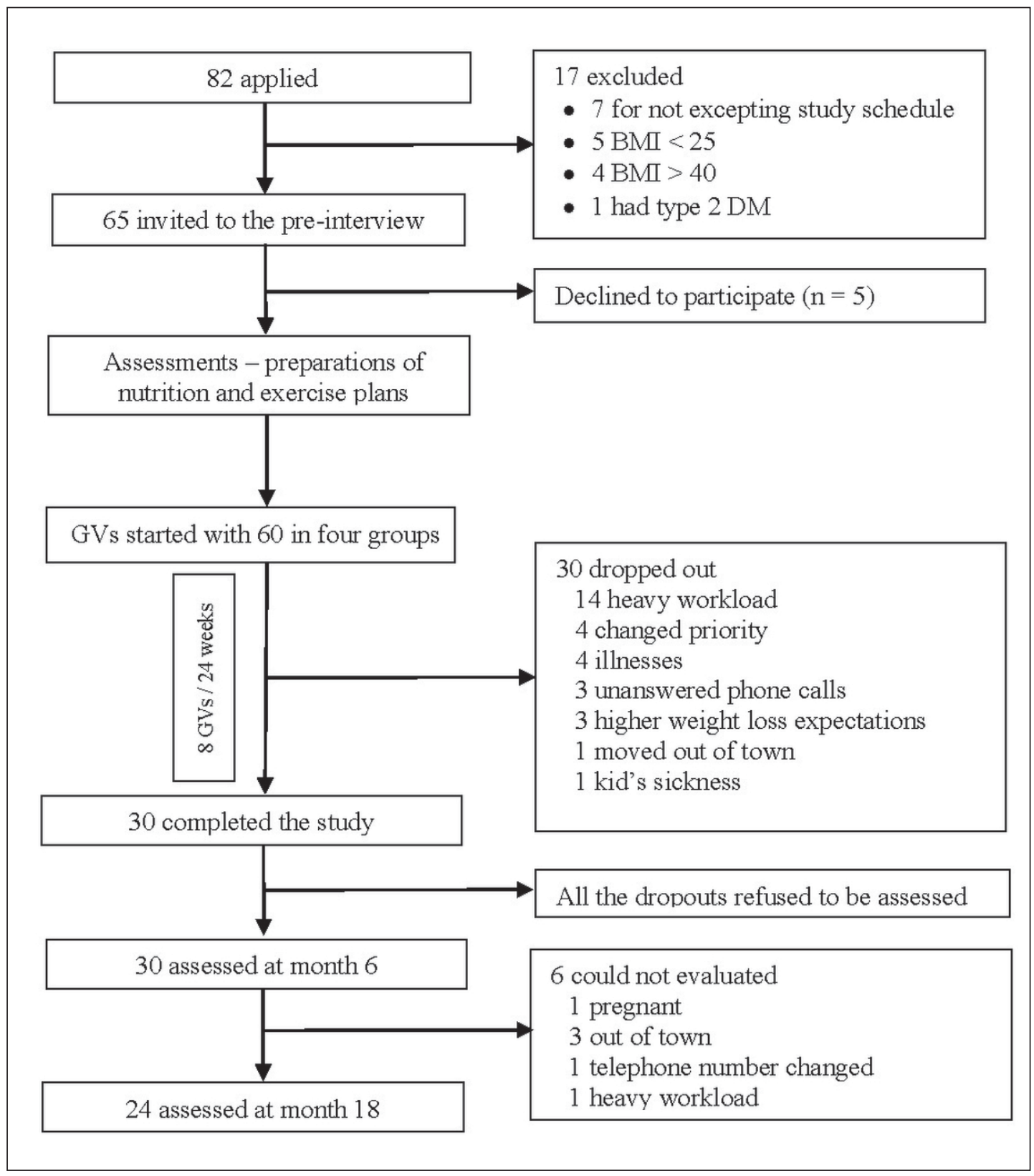

Fig. 1. Study design.

\section{Participants}

The participants were recruited between December 2013 and January 2014 through an advertisement poster and an internet blog that contained study protocol and contact information. The study was announced by the posters hung on three family health centers, the university campus, and the dormitory. The inclusion criteria were defined as follows: women aged 18 years of age and older, BMI between 25 and $40 \mathrm{~kg} / \mathrm{m}^{2}$, ability to speak and read Turkish and having no problems completing the questionnaires and check lists, and absence of secondary obesity. To evaluate the inclusion criteria, physical examination as well as plasma cortisol, thyroid-stimulating hormone (TSH), free thyroxin (fT4), fasting plasma glucose, and glycated hemoglobin (HbA1c) tests were performed. The design of the study is shown in fig. 1. The participants were divided into four groups including 15 individuals by initially considering their preferred GV day. The groups, which became smaller due to dropouts after the 3rd and 4th meetings, were combined, and the GVs were continued 
Tunay et al.: Family Physician-Led Group Visits for Lifestyle Modification in Women with Weight Problems: A Pilot Intervention and Follow-Up Study

with two groups (fig. 1). The individuals who missed the meetings were allowed to participate in the other group's meeting. This happened for 6 participants and only for 1 meeting.

\section{Intervention Content}

The treatment of overweight individuals is based on a comprehensive lifestyle intervention [9-11]. The aim of the present study was to create a comprehensive intervention strategy including lifestyle modification/behavioral training, a regular and balanced diet to reduce energy intake, and an increase of physical activity. Total energy expenditure was determined by adding the energy requirements, which comply with individual exercise plans and daily activities, to the measured resting metabolic rate (RMR). The energy gap required to achieve individual body weight targets within the study period was calculated. The diet content was determined considering lipid profiles and food preferences of the participants to be able to achieve a balanced and suitable diet. The nutrition plan was composed of 50- 55\% carbohydrates, 15-20\% proteins, and $25-30 \%$ fats $[12,13]$. The participants were encouraged to modify their nutrition style to a balanced form as well as to decrease consumption of high glycemic index food and to increase the intake of fiber, vegetables, and fruits. Three main meals and optionally two or three snacks were recommended. The participants were taught to identify the content and the amount of their food in a way that enable them to individually balance calorie intake. For this purpose, a table of basic food samples describing a portion of carbohydrate, fat, protein, or dairy products as well as the weights of vegetables and fruits cooked or uncooked and their approximate frequency of consumption was distributed to participants.

The physical activity program was prepared after calculation of exercise intensity and the pulse range where fat burning is at the highest level according to the cardiopulmonary exercise test (CPET). The participants were asked to follow the exercise program which should be no less than 20 min once and no longer than $60 \mathrm{~min}$ in a day for at least 3 days a week. They were advised to start walking with the lowest frequency and duration according to their conditions. Heart rate monitoring watches with chest bands were distributed to the participants to keep their heart rate within the pre-determined range.

GVs were structured on the basis of the transtheoretical model and social cognitive learning theories. Within this context and besides nutritional education, behavioral treatment techniques including motivational interviewing, incremental goalsetting, self-monitoring of the eating and physical activity pattern, stimulus control, problem solving, cognitive re-structuring were performed, giving also room obstacles, questions, and emotions. Problem solving skill, noticing automated thoughts, putting certain and achievable targets and self-monitoring studies were also introduced [14-17]. The first session started with a presentation of general information. Subsequently, an agenda was developed to include practical implementations by considering expectations and needs of the participants. Each participant provided a self-monitoring log containing i) two separate zero to ten scales ranking the level of importance they give healthy lifestyle change and how confident they are in making these changes, ii) their individual motivations for change, iii) check tables to fill daily consumed food portions and exercises, iv) a guided tool for problem-solving practices, v) a table of food groups and portion sizes, and vi) empty pages for taking notes on their obstacles and questions that may arise. Content and agenda of the GVs were presented in table 1. Only self-monitoring was used to check the compliance with intervention delivery in order to avoid emphasizing external control in behavioral changes. The primary target of the participants in the present study was to focus on healthy lifestyle adoption, and not on weight loss. Therefore, weight monitoring was performed at the beginning and at the end of 6 th month. The interviews focused on compliance to the individual plans, the obstacles faced, and problemsolving exercises instead of changes in the body weight.

\section{Facilitators}

The GVs were performed by a facilitator (second author), a research fellow, and a nurse. The interview for problem-solving skills was conducted with the support of another facilitator (third author). The same facilitators delivered the sessions to each group of participants throughout the intervention for all groups. Both facilitators, who work as faculty members in the family medicine department, were female, had completed a 88-hour cognitive behavioral training and were used to perform GVs for patients with hypertension and diabetes. At the end of each GV, the second author performed the one-on-one interviews (if needed).

Data Sources / Collection

Data were obtained by anthropometric measurements, SF-36 scale [18], CPET, RMR, resting heart rate (RHR), blood pressure (BP), and measurement of blood parameters such as high-sensitivity C-reactive 
Table 1. Group visits content and agenda

GVs no.

\begin{tabular}{|c|c|c|}
\hline & & GVs no. \\
\hline Preparation $\approx 30 \mathrm{~min}$ & $\begin{array}{l}\text { Name tags, sing in sheets, agenda outline, medical patient records, } \\
\text { educational materials, large \& medium size BP cuffs, refreshments, } \\
\text { U-shape room setup, audio recorder }\end{array}$ & all \\
\hline \multirow[t]{2}{*}{$\begin{array}{l}\text { Registry \& introduction } \\
\approx 20 \mathrm{~min}\end{array}$} & $\begin{array}{l}\text { Introduction of the group visit outline, confidentiality contracts, } \\
\text { nametags \& self-monitoring records for food and exercise } \\
\text { distribution }\end{array}$ & 1 \\
\hline & $\begin{array}{l}\text { Attendance list, } \mathrm{BP} \text { and heart rate measurement, pre-review of the } \\
\text { self-monitoring records }\end{array}$ & all \\
\hline \multirow[t]{8}{*}{$\begin{array}{l}\text { Interactive presentations } \\
\approx 35 \mathrm{~min}\end{array}$} & $\begin{array}{l}\text { Health effects of weight problem, understanding behavior and } \\
\text { change levels, }\end{array}$ & 1 \\
\hline & $\begin{array}{l}\text { Nutritional items, glycemic index, portion tracking, adequate- } \\
\text { balanced-regular nutrition, recognize and note obstacles and } \\
\text { triggers }\end{array}$ & 2 \\
\hline & Problem solving skills & 3 \\
\hline & $\begin{array}{l}\text { Creating healthy meals and a positive eating environment and, } \\
\text { healthy cooking strategies }\end{array}$ & 4 \\
\hline & Popular diet programs and possible side effects & 5 \\
\hline & $\begin{array}{l}\text { Practice for strength and stretching exercises in the field } \\
\text { (brochures provided) }\end{array}$ & 6 \\
\hline & $\begin{array}{l}\text { Practice for stress management, relaxation exercises, problem } \\
\text { management }\end{array}$ & 7 \\
\hline & Discussing the strategies for sustaining behavior change & 8 \\
\hline \multicolumn{3}{|c|}{ Break/healthy snack (15 min) } \\
\hline \multirow[t]{2}{*}{$\mathrm{Q} \& \mathrm{~A} \approx 40 \mathrm{~min}$} & Discussion and sharing experiences & \\
\hline & Problem solving small group exercises & $\begin{array}{l}3,4,5,7, \\
8\end{array}$ \\
\hline Closure $\approx 10 \mathrm{~min}$ & Summary, setting assignments and planning next session's themes & all \\
\hline $\begin{array}{l}\text { Individual consultation } \\
\approx 30 \mathrm{~min}\end{array}$ & One-on-one assessments with whose needed & all \\
\hline
\end{tabular}

protein (HsCRP), complete blood count, $\mathrm{HbA}_{1 \mathrm{c}}$, fasting plasma glucose, total cholesterol (TC), triglyceride level, low-density lipoprotein (LDL) and high-density lipoprotein (HDL) cholesterol, insulin, TSH, free T4. All measurements were performed at the beginning and end of the intervention. Height $(\mathrm{m})$ body weight $(\mathrm{kg})$ was measured to the nearest $0.1 \mathrm{~cm}$ and $20 \mathrm{~g}$, respectively, was measured with participants dressed in only light clothes (and no shoes). Waist circumference measurement was done with the individual at a standing position with relaxed abdomen, arms hanging on sides, legs next to each other with a measuring tape over the belly button at the end of expirium. Hip circumference was measured with the patient in the same position during waist circumference measurement with the tape placed parallel to the ground on the widest spot of the hip.

$\mathrm{BP}$ and pulse were measured from the upper arm using an Omron device (Kyoto, Japan).

RMR was measured using a Cosmed Quark $\beta^{2}$ gas analyzer through indirect calorimetric method by the Sport Physiology Laboratory staff of Çukurova University, Faculty of Medicine. Participants were advised to stop training $24 \mathrm{~h}$ before the measurements. The measurements were performed in the morning after a fasting period of at least $12 \mathrm{~h}$ after a complete overnight rest. A silent and somber environment was provided. The gas analysis was performed at supine lying position through a facemask by supporting the head and back 
Table 2. Socio-demographic characteristics of the fullattenders in comparison with the dropouts
Tunay et al.: Family Physician-Led Group Visits for Lifestyle Modification in Women with Weight Problems: A Pilot Intervention and Follow-Up Study

\begin{tabular}{|c|c|c|c|}
\hline & $\begin{array}{l}\text { Full attenders } \\
(\mathrm{n}=30)\end{array}$ & $\begin{array}{l}\text { Dropouts } \\
(\mathrm{n}=30)\end{array}$ & $\mathrm{p}^{*}$ \\
\hline Full-time employment & $12(40.0)$ & $19(63.3)$ & \multirow{2}{*}{0.114} \\
\hline Unemployed & $18(60.0)$ & $11(36.7)$ & \\
\hline Has a health insurance & $29(96.6)$ & $28(93.3)$ & \multirow{2}{*}{0.999} \\
\hline No health insurance & $1(3.4)$ & $2(6.7)$ & \\
\hline Lives with a partner & $21(70.0)$ & $20(66.7)$ & \multirow{2}{*}{0.999} \\
\hline No current partner & $9(30.0)$ & $10(33.3)$ & \\
\hline High school or lower education & $7(23.3)$ & $15(50.0)$ & \multirow{2}{*}{0.060} \\
\hline Higher education then high school & $23(76.7)$ & $15(50.0)$ & \\
\hline
\end{tabular}

lordosis with a pillow. An incremental CPET was performed to detect the highest fat-burning levels of the individuals. Since the participants have a sedentary lifestyle, the rate of the treadmill was started at $3 \mathrm{~km} / \mathrm{h}$ and increased by $0.5 \mathrm{~km} / \mathrm{h} / \mathrm{min}$ [19]. The heart rate and exercise intensity which corresponds to maximal fat oxidation (Fatmax) were calculated. Each participant was instructed about their minimum and maximum heart rates for individualized Fatmax exercise prescription [20].

For weight maintenance evaluation, the anthropometric measurements were rerun after 1 year from the onset of the study, and the participants were asked to fill an inventory including individual nutrition and walking routines. The overall compliance to the food items was determined by asking the participants to rank their compliance with the provided options of less, more or full. Physical activity levels were assessed by asking when they started regular walking, how many minutes a week they walked, and whether they did any exercise other than walking.

At the end of the study, participants were asked whether or not they would like to participate in such GVs in the future or would recommend to others.

\section{Data Analysis}

Homogeneity of the data distribution of the study was analyzed by the Kolmogorov Smirnov test. Paired t-test and Wilcoxon's test were used to evaluate the differences within the participants before and after GVs. The in-group evaluations were done using the Mann-Whitney U test. Evaluation of the demographic data was done with Ki-square and Fisher's exact test. Spearman's $\rho$ coefficient was used as a correlation measure. The significance was set at a level of 0.05 (two-tailed), and the confidence range was determined as $95 \%$.

\section{Results}

The GVs started with 60 volunteers who were in accordance with the study criteria from the applicant pool. Half of the participants completed the 24 -week program. The average age of the completers and dropouts was $37.4 \pm 9.7$ and $36.7 \pm 8.6$ years, respectively $(p=0.478)$; their sociodemographic characteristics and SF-36 measurements were similar (tables 2, 3). A total of eight GVs were done with 30 participants who participated to all interviews. The interviews lasted about $95 \mathrm{~min}$. The average duration of a GV including preparations, personal interviews for those who need, and file recording was $210 \mathrm{~min}$. Among the participants, $56.7 \%(n=17)$ had obesity history in the family, and $16.7 \%(n=5)$ were smokers. $70 \%$ of the participants did not have any other concomitant disease. Three participants had bronchial asthma, 3 participants had primary hypertension, 1 participant had polycystic ovarian syndrome, and 1 patient had Raynaud's disease. 
Table 3. Comparison of the SF- 36 quality of life scales at the beginning and end of the study

\begin{tabular}{|c|c|c|c|c|c|}
\hline \multirow[t]{3}{*}{ SF-36 } & \multicolumn{3}{|c|}{ Scores (means \pm SD) } & \multirow[t]{3}{*}{$\mathrm{p}^{@}$} & \multirow[t]{3}{*}{$\mathrm{p}^{\#}$} \\
\hline & \multicolumn{2}{|c|}{ full attenders $(n=30)$} & \multirow{2}{*}{$\frac{\text { dropouts }(n=29)}{\text { initial }}$} & & \\
\hline & initial & final & & & \\
\hline Physical functioning & $79.0 \pm 17.6$ & $87.5 \pm 9.1$ & $74.5 \pm 18.5$ & 0.011 & 0.188 \\
\hline Role physical & $69.2 \pm 33.9$ & $79.2 \pm 31.5$ & $57.8 \pm 39.6$ & 0.194 & 0.358 \\
\hline Bodily pain & $61.3 \pm 27.8$ & $77.3 \pm 18.6$ & $53.4 \pm 28.0$ & 0.005 & 0.337 \\
\hline General health & $55.8 \pm 23.3$ & $68.2 \pm 17.0$ & $58.9 \pm 21.3$ & 0.006 & 0.750 \\
\hline Vitality & $53.2 \pm 25.6$ & $62.0 \pm 21.4$ & $51.7 \pm 19.1$ & 0.048 & 0.796 \\
\hline Social functioning & $70.4 \pm 21.4$ & $78.3 \pm 21.8$ & $70.7 \pm 26.8$ & 0.051 & 0.660 \\
\hline Role emotional & $51.1 \pm 25.9$ & $63.3 \pm 22.1$ & $54.0 \pm 31.4$ & 0.023 & 0.554 \\
\hline Mental health & $63.7 \pm 21.8$ & $71.9 \pm 18.4$ & $60.3 \pm 17.7$ & 0.041 & 0.326 \\
\hline Physical Component Summary & $46.8 \pm 8.5$ & $51.5 \pm 4.7$ & $44.4 \pm 8.6$ & 0.002 & 0.197 \\
\hline Mental Component Summary & $42.3 \pm 10.1$ & $46.0 \pm 9.7$ & $42.8 \pm 9.3$ & 0.044 & 0.885 \\
\hline
\end{tabular}

${ }^{\circledR}$ Initial and final scores of full attenders Wilcoxon sign test.

\#Initial scores of full attenders and dropouts Mann-Whitney U test.

A significant decrease was detected in the average weight measured at the beginning of GVs as an immediate effect of interventions after the 6th month (table 3). 21 (70\%) patients lost more than $5 \%$ of initial body weight, whereas $13(43.3 \%)$ patients lost more than $10 \%$ of the initial body weight. Two participants (according to their own expression) lost weight within first months and completed the 6th month by gaining weight ( $1.3 \mathrm{~kg}$ and $3.9 \mathrm{~kg})$. Mean weight loss was calculated as $8.2 \%$. Mean weight change over 24 weeks was $-6.9 \pm 5.0 \mathrm{~kg}$. A regression of BMI of at least one unit was detected in $93.3 \%$ of the participants (min-max = 7-1). Mean BMI, waist circumference, hip circumference, and waist-to-height ratio (WHtR) significantly decreased $(\mathrm{p}<0.001)$, but not mean waist-to-hip ratio (WHR). As shown in table 3, there was an overall decrease in TC, LDL cholesterol, triglyceride, HBA1c, and insulin levels, but none of these changes reached statistical significance $(p>0.05)$. However, all 7 participants who had $\mathrm{HbA1C}$ levels over $6 \%$ achieved a drop of the parameter to reference values. The increase of $2.7 \pm 6.2 \mathrm{mg} / \mathrm{dl}$ in mean HDL cholesterol levels and the decrease of TC in proportion to HDL cholesterol were found to be significant $(p<0.05)$. Systolic BP, diastolic $\mathrm{BP}$, and RHR levels of the participants were significantly lower at the end of the study $\mathrm{p}=$ $0.006, p=0.001$ and $p=0.012$, respectively). There was no significant change in aerobic pulse ranges, which were determined by CPET $(p>0.05)$. All the subscales (except 'role physical' and 'role emotional') and physical (PCS) and mental component summary scales (MCS) of the baseline SF-36 scores of the completers were improved at the end of the study (table 4).

The ratio of the participants who could comply with the regular exercise program longer than 3 months was $80 \% .13 .3 \%$ of the participants stated that they only exercised regularly in the last 2 months, and $6.7 \%$ did not exercised regularly. When the self-declared compliance of the participants with balanced diet program was investigated, $90 \%$ had a compliance with vegetables, dairy products and glycemic index; $83.3 \%$ had compliance with protein; $80 \%$ had compliance with fruits, $60 \%$ had compliance with fat, and $66.7 \%$ had a compliance with carbohydrate groups. The ratio of those who had full coherence (coherent for $\geq 6$ nutrition units) was found as $53.3 \%$. The group that complied with the protein and fat portion counts of their nutrition plan and chose to eat food with low glycemic index lost significantly more weight than those who did not ( $p=0,004, p=0.006, p=0.036$, respectively) (table 5). When the association between compliance with the nutrition program and SF-36 scores were investigated, a significantly lower MCS score was detected in the non-compliant group relative to 
Tunay et al.: Family Physician-Led Group Visits for Lifestyle Modification in Women with Weight Problems: A Pilot Intervention and Follow-Up Study

Table 4. Changes in selected clinical and metabolic variables from baseline to follow-up at 6 months among completers of the study $(n=30)$

\begin{tabular}{|c|c|c|c|c|}
\hline & \multirow{2}{*}{$\frac{\text { Baseline }}{\text { mean } \pm \text { SD }}$} & \multicolumn{2}{|l|}{ 6th month } & \multirow[t]{2}{*}{ p value $e^{\S}$} \\
\hline & & mean \pm SD & + value & \\
\hline Weight, kg & $84.7 \pm 13.8$ & $77.8 \pm 14.1$ & -6.9 & $0.001^{*}$ \\
\hline BMI, $\mathrm{kg} / \mathrm{m}^{2}$ & $31.6 \pm 4.2$ & $29.0 \pm 4.4$ & -2.6 & 0.001 \\
\hline Waist circumflex, cm & $99.8 \pm 9.1$ & $93.7 \pm 10.0$ & -6.1 & $0.001^{*}$ \\
\hline Hip circumflex, cm & $114.5 \pm 9.6$ & $108.2 \pm 10.2$ & -4.3 & $0.001^{*}$ \\
\hline WHR, \% & $0.87 \pm 0.7$ & $0.87 \pm 0.6$ & -0.6 & $0.221^{*}$ \\
\hline WHtR, \% & $0.61 \pm 0.1$ & $0.57 \pm 0.1$ & -0.04 & $0.001^{*}$ \\
\hline FPG, mg/dl & $85.1 \pm 10.7$ & $90.8 \pm 8.5$ & 5.7 & 0.001 \\
\hline HbA1c, \% & $5.5 \pm 0.5$ & $5.4 \pm 0.3$ & -0.1 & 0.428 \\
\hline $\mathrm{TC}, \mathrm{mg} / \mathrm{dl}$ & $178.7 \pm 36.9$ & $176.8 \pm 31.5$ & -1.9 & 0.804 \\
\hline $\mathrm{HDL}, \mathrm{mg} / \mathrm{dl}$ & $43.2 \pm 10.6$ & $46.0 \pm 9.6$ & 2.8 & 0.022 \\
\hline TC / HDL-C, mg/dl & $4.3 \pm 1.1$ & $3.9 \pm 0.8$ & -0.4 & $0.003^{*}$ \\
\hline Triglyceride, mg/dl & $96.8 \pm 52.9$ & $86.7 \pm 45.7$ & -10.1 & 0.258 \\
\hline $\mathrm{LDL}, \mathrm{mg} / \mathrm{dl}$ & $115.2 \pm 28.8$ & $113.5 \pm 24.8$ & -1.7 & 0.689 \\
\hline Insulin, $\mu \mathrm{U} / \mathrm{ml}$ & $7.7 \pm 4.4$ & $7.5 \pm 3.3$ & -0.2 & 0.845 \\
\hline TSH, mIU/l & $1.9 \pm 1.2$ & $1.6 \pm 1.2$ & -0.3 & 0.009 \\
\hline $\mathrm{fT} 4, \mathrm{ng} / \mathrm{dl}$ & $0.9 \pm 0.1$ & $0.8 \pm 0.1$ & -0.1 & 0.024 \\
\hline HsCRP, mg/l & $0.5 \pm 0.5$ & $0.5 \pm 0.5$ & 0 & 0.572 \\
\hline Homa IR & $1.6 \pm 0.9$ & $1.7 \pm 0.8$ & 0.1 & 0.869 \\
\hline Hr-min & $112.0 \pm 13.4$ & $113.8 \pm 14.9$ & 1.8 & 0.566 \\
\hline Hr-max & $117.8 \pm 12.7$ & $120.3 \pm 14.1$ & 2.5 & 0.396 \\
\hline RMR, kcal & $1292.8 \pm 364.0$ & $1224.3 \pm 324.5$ & 68.5 & 0.086 \\
\hline Predicted RMR \% & $0.8 \pm 0.2$ & $0.8 \pm 0.2$ & 0 & 0.446 \\
\hline $\mathrm{RQ}$ & $0.8 \pm 0.1$ & $0.8 \pm 0.1$ & 0 & 0.563 \\
\hline $\mathrm{Fat}^{\#}, \%$ & $57.8 \pm 21.6$ & $59.9 \pm 16.8$ & 2.1 & 0.676 \\
\hline Carbohydrate ${ }^{\#} \%$ & $42.5 \pm 21.6$ & $40.5 \pm 16.9$ & -2.0 & 0.682 \\
\hline Systolic blood pressure & $118.1 \pm 13.2$ & $111.1 \pm 12.4$ & -7.0 & 0.006 \\
\hline Diastolic blood pressure & $74.5 \pm 12.7$ & $68.3 \pm 11.5$ & -6.2 & 0.001 \\
\hline Heart rate & $77.4 \pm 13.7$ & $70.0 \pm 9.2$ & -7.4 & 0.012 \\
\hline
\end{tabular}

Hr-min = Lower limit of hearth rate for fat max; Hr-max = higher limit of hearth rate for fat max; RMR = resting metabolic rate; $\mathrm{RQ}=$ respiratory quotient.

§Wilcoxon sign test.

*Paired sample T test.

\# Ratio of the substrates burned at rest.

the compliant group. Spearman's correlations were run to determine the relationship between initial SF-36 and weight loss and coherence to nutritional plan. There were moderate, positive monotonic correlations between initial MCS and both full coherence $\left(r_{s}=0.43 ; p=0.02\right)$ and weight loss $\left(r_{s}=0.42 ; p=0.02\right)$. A moderate association was found between weight loss and weekly exercise durations (fig. 2). There was no significant association between weight loss and marital status, educational level, occupation, any other exercises beyond walking, obesity history in the family, smoking or concomitant diseases.

To evaluate the maintenance of weight loss 48 weeks after the onset of the study, an attempt to contact the participants was made. Measurements of 6 participants could not be performed because one was pregnant, one participant's phone number was cancelled and 3 participants were out of the city. 24 participants were available for follow-up at the 12 th week. Their mean body weight was $3.8 \mathrm{~kg}$ higher than at 24 th week $(81.6 \pm 15.9 \mathrm{~kg})$. Ratios in terms of maintenance of the weight lost revealed that $75 \%$ of the participants preserved at 
Table 5. The relationship between coherence to the individualized nutrition plans with weight loss and SF 36 scores

\begin{tabular}{|c|c|c|c|}
\hline \multirow[t]{2}{*}{ Nutritional content (portion) } & \multicolumn{2}{|c|}{ Weight loss, mean \pm SD (n) } & \multirow[t]{2}{*}{ p value } \\
\hline & coherent & incoherent & \\
\hline Protein & $8.1 \pm 4.4(25)$ & $1.0 \pm 3.5(5)$ & 0.004 \\
\hline Dairy product & $7.0 \pm 4.7(27)$ & $6.1 \pm 9.0(3)$ & 0.604 \\
\hline Vegetable & $7.5 \pm 4.9(27)$ & $2.0 \pm 2.9(3)$ & 0.057 \\
\hline Fruit & $6.3 \pm 3.9(24)$ & $9.5 \pm 8.0(6)$ & 0.325 \\
\hline Carbohydrate & $8.0 \pm 4.9(20)$ & $4.8 \pm 4.7(10)$ & 0.135 \\
\hline Fat & $9.0 \pm 4.5(18)$ & $3.8 \pm 4.1(12)$ & 0.006 \\
\hline Glycemic index & $8.9 \pm 4.5(27)$ & $5.0 \pm 4.8(3)$ & 0.036 \\
\hline \multirow[t]{3}{*}{ Full coherence ${ }^{*}$} & $8.8 \pm 4.3(16)$ & $4.8 \pm 5.1(14)$ & 0.025 \\
\hline & \multicolumn{2}{|c|}{ SF-36 summary scales, mean \pm SD (n) } & \\
\hline & fully coherent & incoherent & \\
\hline $\mathrm{PCS}_{1}$ & $47.6 \pm 8.7(16)$ & $45.99 \pm 8.5(14)$ & 0.442 \\
\hline $\mathrm{MCS}_{1}$ & $47.2 \pm 7.0(16)$ & $36.69 \pm 10.4(14)$ & 0.005 \\
\hline $\mathrm{PCS}_{2}$ & $52.4 \pm 3.5(16)$ & $50.5 \pm 5.8(14)$ & 0.318 \\
\hline $\mathrm{MCS}_{2}$ & $49.7 \pm 5.6(16)$ & $41.8 \pm 11.6(14)$ & 0.105 \\
\hline
\end{tabular}

$\mathrm{PCS}_{1}=$ SF-36 Physical Component Summary Scale at the beginning of the intervention; $\mathrm{MCS}_{1}=\mathrm{SF}-36$ Mental Component Summary Scale at the beginning of the intervention; PCS $_{2}=$ SF-36 Physical Component Summary Scale at the end of the intervention; $\mathrm{MCS}_{2}=$ SF-36 Mental Component Summary Scale at the end of the intervention.

§Mann-Whitney U test.

*Coherence to six out of seven nutritional contents accepted as full coherence.

least one unit reduction in BMI; $62.5 \%$ of the participants continued to lose weight or gained $3 \mathrm{~kg}$ at most; and $58.3 \%$ of them preserved $\geq 5 \%$ of initial body weight.

$91.6 \%(n=22)$ of these participants declared that they either would like to participate GVs in the future or recommend them to others.

\section{Discussion}

\section{Effects of Family Physician-Led GV Intervention in Weight Loss and Maintenance}

It is reported in different randomized controlled trials and reviews that group-based comprehensive lifestyle changing programs provide an average weight loss of $2-10 \mathrm{~kg}$ within 6 months [7, 21-25]. The primary objective of the present study was to investigate the effect of group interviews which were performed by family practitioners to provide a healthy lifestyle change for weight loss and weight loss maintenance in obese and overweight women. The great majority of our participants lost weight $(-6.9 \pm 5.0 \mathrm{~kg})$, and more than half of them maintained it in the 6-month non-supervised period.

One of the significant findings of the study was that RMR was decreased in our participants, as expected, but this decrease did not reach statistical significance. As MacLean et al. [26] suggested, weight loss leads to a reduction in size of adipocytes, and this decline in size alters the participants' metabolic and inflammatory characteristics in a manner that facilitates the clearance and storage of ingested energy. Thus, one of the results of weight loss from 
Fig. 2. Correlation between weekly exercise duration and body weight change in 6 months.
Tunay et al.: Family Physician-Led Group Visits for Lifestyle Modification in Women with Weight Problems: A Pilot Intervention and Follow-Up Study

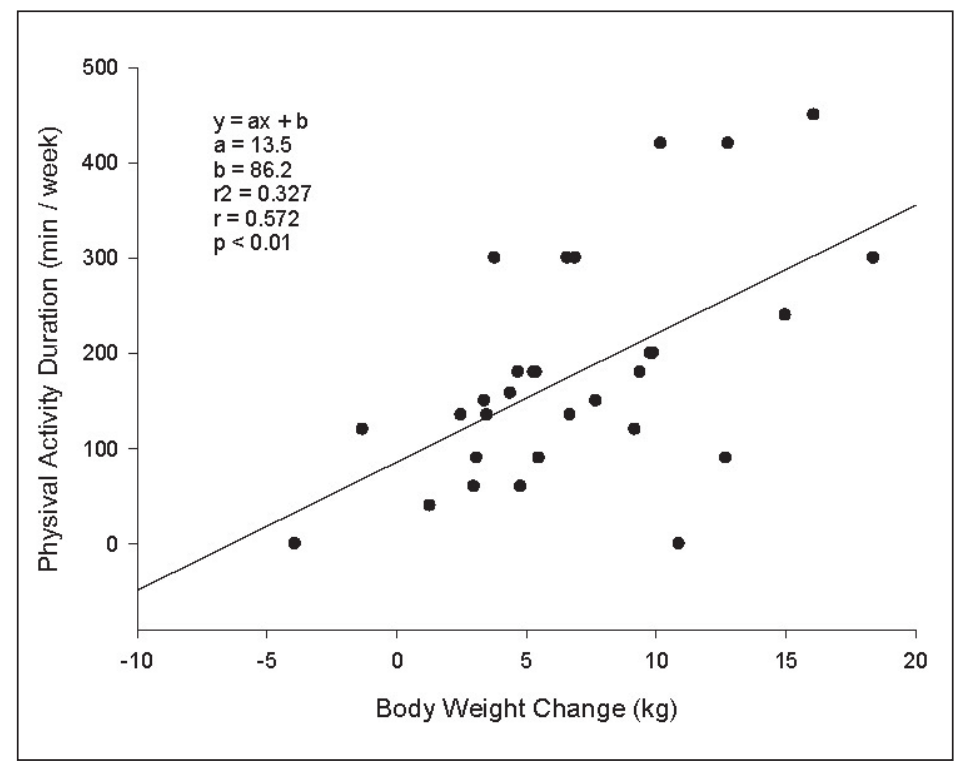

caloric restriction is a substantial change that prime adipose tissues to take up and store ingested energy [27, 28]. It may be argued that the maintenance of RMR may protect patients from weight cycling and may be useful during short-term body weight control.

\section{Effect of the Weight Loss Obtained as a Result of GVs on Health Parameters of the}

Participants

Ashwell et al. [29] mentioned in their meta-analysis that the WHtR of the individuals from different ethnic origin is more valuable than waist circumference and BMI to show the increased cardiovascular risk. There are more recent studies that promote the use of WHtR as a better and simpler screening tool for prediction of not only cardiovascular risk factors but also 'early health risks' associated with central obesity [30-32]. Therefore, with respect to the decrease in WHtR achieved in the present study, which was below the optimal cut-off value for cardiometabolic risk in the adult Turkish population [33], the risk of suffering from cardiovascular diseases could successfully be reduced in our participants. Furthermore, other indicators of a cardiovascular risk like mean systolic BP, diastolic BP, and RHR also decreased.

An inverse correlation between BMI and fT4 values has been reported even if fT4 values remain in the normal range [34]. Moreover, after weight loss a significant decrease in serum fT3 and TSH levels has also been addressed [35]. Even though it may be seen clinically insignificant, the study by Sarl et al. [36] suggests that $>10 \%$ weight loss in 6 months may affect thyroid volume and function. In our study, a significant decrease was detected in TSH and fT4 results although these decreases remained within the normal reference range.

The decreases in TC, LDL cholesterol and triglyceride levels were not statistically significant. However, the increase in the mean HDL cholesterol level and the decrease in the ratio of TC to HDL cholesterol were found to be significant. The 2016 European Society of Cardiology/European Atherosclerosis Society Guidelines for the Management of Dyslipidemias reports that weight reduction has a beneficial influence on HDL cholesterol levels: a 0.4 $\mathrm{mg} / \mathrm{dl}$ increase is observed for every kilogram of decrease in body weight after weight reduction has stabilized [37]. The 2013 American Heart Association/American College of Cardiology/The Obesity Society Guideline for the Management of Overweight and Obesity in 
Adults also reveals that a sustained weight loss of 5-8 kg results in a mean increase in HDL cholesterol of 2-3 mg/dl [9] The HDL cholesterol response to physical activity appears to be influenced by the physical activity's volume and intensity. Baseline HDL cholesterol and gender also affects the individual responses [38]. In general, there are greater HDL cholesterol responses to exercise training in those who have relatively low HDL cholesterol levels as observed in our study, which may help to explain the significant increase in mean HDL cholesterol [39]. The amount of aerobic exercise needed to produce significant HDL cholesterol changes is estimated at approximately 1,000-1,500 kcal/ week (i.e., 7-14 miles/week of walking or jogging) $[40,41]$. Thus, the increase in HDL cholesterol induced by mean weight loss and endurance training in our study seems in line with the literature when considering the relatively low initial HDL cholesterol levels in our participants.

\section{Effect of Weight Loss Obtained after GVs on Quality of Life of the Participants}

It is known that overweight has varying psychosocial effects in individuals. Since the majority of the obese individuals gain weight slowly and insidiously, they are not aware of the important consequences of this weight gain for their quality of life. Fontaine and Barofsky [42] emphasized that health-related quality of life evaluations may help obese individuals redefining treatment goals beyond weight loss and this may help shifting the focus from simple weight reduction to a behavioral change resulting in a healthier lifestyle. In our study, the SF-36 scale revealed a significant increase in PCS and MCS, which was in accordance with the results of similar studies [42-46]. These results support the hypothesis that interventions focusing on lifestyle changes may be effective in overweight and obese women in improving quality of life, especially in physical and mental function fields.

\section{Association of the Weight Loss Obtained after GVs with Compliance to Diet and Exercise Recommendations}

Since a portion-based diet program was planned for the participants in the present study, the association between weight loss and compliance to the portions was analyzed. According to the participants' responses, a significant association was observed between weight loss and compliance to the portions, including protein, fat, and foods with low glycemic index. A significant difference in weight loss was detected between the individuals who complied with at least one of food groups and those who did not comply. Another prominent finding of the present study was the lower compliance of the participants with lower MCS score detected at the beginning of the study. In light of the correlation between weight loss and compliance to the dietary plan, planning of appropriate prevention procedures or alternative individual methods aside from the GVs for individuals that have lower MCS scores should be considered.

Although the GVs included a period of 6 months in the present study, the participants took time to adopt their lifestyles in terms of diet and exercise onto a desired level. However, $80 \%$ of the participants expressed that they managed to follow the exercise periods given for 3 months and longer. There was a significant association between exercise duration per week and weight loss. Since pulse rates of the participants determined for fat burning (especially those who have a more sedentary lifestyle) correspond to a slow walking tempo, the participants did not believe that such slow tempo would cause weight loss at first. These participants either did not follow the program sufficiently or did heavier exercises than recommended because they believed that walking faster or running is required to lose weight. The participants who strictly follow their given pulse range shared their experiences in the GVs expressing that their resting pulse rates decreased and that they needed to expend more effort to increase their pulse rates again. This assured compliance of those who believed the opposite. 
Tunay et al.: Family Physician-Led Group Visits for Lifestyle Modification in Women with Weight Problems: A Pilot Intervention and Follow-Up Study

\section{Conclusion}

The present study is the first research conducted in our country in primary care. Even though the study has a small sample size, it possesses the strengths of a theory-based structure and a detailed description of the intervention. Furthermore the findings of this study suggest that the majority of the participants find GVs beneficial and would recommend them to others. This may imply that GVs might be acceptable for the populations similar to that in this study. On the other hand, the high number dropouts may be considered as limitation of this study. The fact that the meetings were held during working hours, might have an influence on participation as $63 \%$ of the group of participants who did not attend the GVs were working fulltime. Another major obstacle might be that the meetings were held in the university campus, which is far from the city center. Arranging such healthcare services with flexible times and in centers close to urban areas would probably increase participation and feasibility. The underlying causes of high dropouts and individual differences were further assessed in another qualitative study where in-depth interviews took place.

Since the GVs were carried out with women who are at preparation stage of behavioral change, the results were limited to this specific group. It is obvious that the reproducibility of this model depends on the family physicians managing the GV, on their basic understanding of the related behavioral theories, and on their skills to initiate healthy lifestyle modifications in the participants. In conclusion, family physician-led GVs seem to be a feasible approach to induce weight loss and to promote short-term lifestyle changes at least in women who are at the preparation phase of behavioral change and do not have emotional challenges as these may lower scores in the MCS. Finally, it is important for healthcare providers to remember that weight management will need continued supervision over a long time since weight problems are chronic conditions.

\section{Acknowledgments}

The research team would like to thank all participants for their valuable contributions and sharing and would also express their gratitude to Betül Karateke for her nursing services throughout the study. The intervention part of this work was supported by the Çukurova University Scientific Research Project with the grant number TF2013LTP32.

\section{Disclosure Statement}

The authors declare no conflict of interest.

\section{References}

1 Butryn ML, Clark VJ, Coletta MC: Behavioral approaches to the treatment of obesity; in Akabas SR, Lederman SA, Moore BJ (eds): Textbook of Obesity: Biological, Psychological and Cultural Influences, ed 1st. West Sussex, Wiley-Blackwell, 2012, pp 253-272.

2 Kringos DS, Boerma WGW, Spaan E, Pellny M: A snapshot of the organization and provision of primary care in Turkey. BMC Health Serv Res 2011;11:90.

3 Deveugele M, Derese A, van den Brink-Muinen A, Bensing J, De Maeseneer J: Consultation length in general practice: cross sectional study in six European countries. BMJ 2002;325:472.

4 Wilson AD, Childs S, Gonçalves-Bradley DC, Irving GJ: Interventions to increase or decrease the length of primary care physicians' consultation. Cochrane Database Syst Rev 2016;8:CD003540.

5 Noffsinger EB: Introduction to group visits; in: Running Group Visits in Your Practice. New York, Springer, 2009, pp 3-19. 
6 Scott JC, Conner DA, Venohr I, Gade G, McKenzie M, Kramer AM, Bryant L, Beck A: Effectiveness of a group outpatient visit model for chronically ill older health maintenance organization members: a 2-year randomized trial of the Cooperative Health Care Clinic. J Am Geriatr Soc 2004;52:1463-1470.

7 Paul-Ebhohimhen V, Avenell A: A systematic review of the effectiveness of group versus individual treatments for adult obesity. Obes Facts 2009;2:17-24.

8 World Medical Association: Declaration of Helsinki: Recommendations guiding physicians in biomedical research involving human subjects. J Am Med Assoc 1997;277:925-926.

9 Jensen MD, Ryan DH, Apovian CM, Ard JD, Comuzzie AG, Donato KA, Hu FB, Hubbard VS, Jakicic JM, Kushner RF, Loria CM, Millen BE, Nonas CA, Pi-Sunyer FX, Stevens J, Stevens VJ, Wadden TA, Wolfe BM, Yanovski SZ, Jordan HS, Kendall KA, Lux LJ, Mentor-Marcel R, Morgan LC, Trisolini MG, Wnek J, Anderson JL, Halperin JL, Albert NM, Bozkurt B, Brindis RG, Curtis LH, DeMets D, Hochman JS, Kovacs RJ, Ohman EM, Pressler SJ, Sellke FW, Shen WK, Smith SC Jr, Tomaselli GF: 2013 AHA/ACC/TOS guideline for the management of overweight and obesity in adults. J Am Coll Cardiol 2014;63:2985-3023.

10 Yumuk V, Tsigos C, Fried M, Schindler K, Busetto L, Micic D, Toplak H: European guidelines for obesity management in adults. Obes Facts 2015;8:402-424.

11 Wass J, Finer N: Action on obesity: comprehensive care for all. Clin Med (Lond) 2013;13:4-5.

12 Agency FS: McCance and Widdowson's The Composition of Foods, Sixth Summary Edition, 6th ed. Cambridge, The Royal Society of Chemistry, 2004.

13 BEBIS: Ebispro for Windows, Stuttgart, Germany; Turkish version BeBiS, version 7.2. İstanbul, Turkey, 2011.

14 Miller WR, Rollnick S: Motivational Interviewing: Helping People Change, 3rd ed. New York, Guilford Press, 2013.

15 Prochaska JO, Velicer WF, Rossi JS, Goldstein MG, Marcus BH, Rakowski W, Fiore C, Harlow LL, Redding CA, Rosenbloom D, Rossi SR: Stages of change and decisional balance for 12 problem behaviors. Heal Psychol 1994;13:39-46.

16 Bandura A: Health promotion by social cognitive means. Health Educ Behav 2004;31:143-164.

17 Hall K, Gibbie T, Lubman DI: Motivational interviewing techniques: facilitating behaviour change in the general practice setting. Aust Fam Physician 2012;41:660-667.

18 Demiral Y, Ergor G, Unal B, Semin S, Akvardar Y, Kıvırcık B, Alptekin K: Normative data and discriminative properties of short form 36 (SF-36) in Turkish urban population. BMC Public Health 2006;6:247.

19 Shook RP, Hand GA, Paluch AE, Wang X, Moran R, Hébert JR, Blair SN: High respiratory quotient is associated with increases in body weight and fat mass in young adults. Eur J Clin Nutr 2015;1-6.

20 Jeukendrup A, Achten J: Fatmax : A new concept to optimize fat oxidation during exercise? Eur J Sport Sci 2001; $1: 1-5$.

21 Waleekhachonloet O-A, Limwattananon C, Limwattananon S, Gross CR: Group behavior therapy versus individual behavior therapy for healthy dieting and weight control management in overweight and obese women living in rural community. Obes Res Clin Pract 2007;1:223-290.

22 Nakata Y, Okada M, Hashimoto K, Harada Y, Sone H, Tanaka K: Comparison of education-only versus groupbased intervention in promoting weight loss: a randomised controlled trial. Obes Facts 2011;4:222-228.

23 Jamal SN, Moy FM, Mohamed MNA, Mukhtar F: Effectiveness of a group support lifestyle modification (GSLiM) programme among obese adults in workplace: a randomised controlled trial. PLoS One 2016;11):e0160343.

24 Butryn ML, Webb V, Wadden TA: Behavioral treatment of obesity. Psychiatr Clin North Am 2011;34:841-859.

25 Sharma M: Behavioural interventions for preventing and treating obesity in adults. Obes Rev 2007;8:441-449.

26 Maclean PS, Higgins JA, Giles ED, Sherk VD, Jackman MR: The role for adipose tissue in weight regain after weight loss. Obes Rev 2015;16:45-54.

27 Amigo I, Fernández C: Effects of diets and their role in weight control. Psychol Health Med 2007;12:321-327.

28 Dulloo AG, Montani J-P: Pathways from dieting to weight regain, to obesity and to the metabolic syndrome: an overview. Obes Rev An Off J Int Assoc Study Obes 2015;16 Suppl 1:1-6.

29 Ashwell M, Gunn P, Gibson S: Waist-to-height ratio is a better screening tool than waist circumference and BMI for adult cardiometabolic risk factors: systematic review and meta-analysis. Obes Rev 2012;13:275-286.

30 Ashwell M, Gibson S: Waist-to-height ratio as an indicator of 'early health risk': simpler and more predictive than using a 'matrix' based on BMI and waist circumference. BMJ Open 2016; 6:e010159.

31 Lee CMY, Huxley RR, Wildman RP, Woodward M: Indices of abdominal obesity are better discriminators of cardiovascular risk factors than BMI: a meta-analysis. J Clin Epidemiol 2008;61:646-653.

32 Browning LM, Hsieh SD, Ashwell M: A systematic review of waist-to-height ratio as a screening tool for the prediction of cardiovascular disease and diabetes: $0 \cdot 5$ could be a suitable global boundary value. Nutr Res Rev 2010;23:247-269.

33 Can AS, Yildiz EA, Samur G, Rakicioğlu N, Pekcan G, Ozbayrakçi S, Palaoğlu KE, Gönen M, Bersot TP: Optimal waist:height ratio cut-off point for cardiometabolic risk factors in Turkish adults. Public Health Nutr 2010;13: 488-495.

34 Knudsen N, Laurberg P, Rasmussen LB, Bülow I, Perrild H, Ovesen L, Jørgensen T: Small differences in thyroid function may be important for body mass index and the occurrence of obesity in the population. J Clin Endocrinol Metab 2005;90:4019-4024.

35 Biondi B: Thyroid and obesity: an intriguing relationship. J Clin Endocrinol Metab 2010;95:3614-3617.

36 Sari R, Balci MK, Altunbas H, Karayalcin U: The effect of body weight and weight loss on thyroid volume and function in obese women. Clin Endocrinol (Oxf) 2003;59:258-262. 
Tunay et al.: Family Physician-Led Group Visits for Lifestyle Modification in Women with Weight Problems: A Pilot Intervention and Follow-Up Study

37 Catapano AL, Graham I, De Backer G, Wiklund O, Chapman MJ, Drexel H, Hoes AW, Jennings CS, Landmesser U, Pedersen TR, Reiner Ž, Riccardi G, Taskinen MR, Tokgozoglu L, Verschuren WM, Vlachopoulos C, Wood DA, Zamorano JL: 2016 ESC/EAS Guidelines for the management of dyslipidaemias. Atherosclerosis 2016;253: 281-344.

38 Kodama S, Tanaka S, Saito K, Shu M, Sone Y, Onitake F, Suzuki E, Shimano H, Yamamoto S, Kondo K, Ohashi Y, Yamada N, Sone H: Effect of aerobic exercise training on serum levels of high-density lipoprotein cholesterol: a meta-analysis. Arch Intern Med 2007;167:999-1008.

39 Couillard C, Després J, Lamarche B, Bergeron J, Gagnon J, Leon AS, Rao DC, Skinner JS, Wilmore JH, Bouchard C: Effects of endurance exercise training on plasma hdl cholesterol levels depend on levels of triglycerides. Atheroscler Thromb Vasc Biol 2001;21:1226-1232.

40 Kokkinos P, Jonathan M: Exercise and physical activity: clinical outcomes and applications. Circulation 2010; 122:1637-1648.

41 Kraus WE, Houmard JA, Duscha BD, Knetzger KJ, Wharton MB, McCartney JS, Bales CW, Henes S, Samsa GP, Otvos JD, Kulkarni KR, Slentz CA: Effects of the amount and intensity of exercise on plasma lipoproteins. N Engl J Med 2002;347:1483-1492.

42 Fontaine KR, Barofsky I: Obesity and health-related quality of life. Obes Rev 2001;2:173-182.

43 Doll HA, Petersen SE, Stewart-Brown SL: Obesity and physical and emotional well-being: associations between body mass index, chronic illness, and the physical and mental components of the SF-36 questionnaire. Obes Res 2000;8:160-170.

44 Lemstra ME, Rogers MR: Improving health-related quality of life through an evidence-based obesity reduction program: the Healthy Weights Initiative. J Multidiscip Healthc 2016;9:103-109.

45 Uritani D, Matsumoto D, Asano Y, Yoshizaki K, Nishida Y, Shima M: Effects of regular exercise and nutritional guidance on body composition, blood pressure, muscle strength and health-related quality of life in communitydwelling Japanese women. Obes Res Clin Pract 2013;7:e155-e163.

46 Arrebola E, Gómez-Candela C, Fernández-Fernández C, Loria V, Muñoz-Pérez E, Bermejo LM: Evaluation of a lifestyle modification program for treatment of overweight and nonmorbid obesity in primary healthcare and its influence on health-related quality of life. Nutr Clin Pract 2011;26:316-321. 